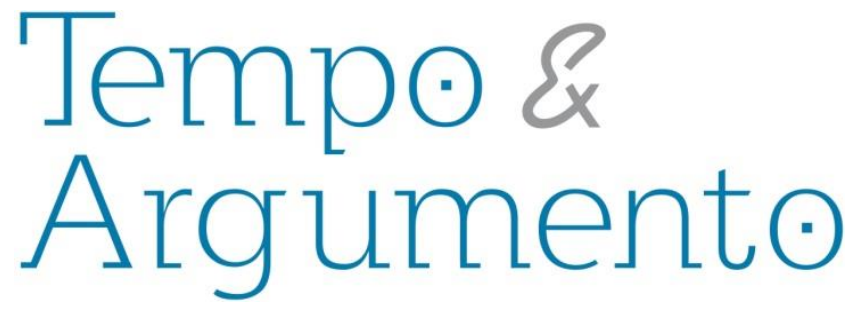

\title{
Fontes telejornalísticas nos domínios de Clio: notas metodológicas
}

\section{Resumo}

O texto enfoca notas teórico-metodológicas voltadas para a análise de produtos telejornalísticos, contemplando as características de sua narrativa, seus recursos e códigos de linguagem, a arquitetura de seus gêneros e formatos, bem como as frentes e fontes de trabalho disponíveis ao historiador. Valendo-se das contribuições de Pierre Bourdieu e dos Estudos Culturais Ingleses é abordado o circuito de relações entre os universos da produção, do texto e da circulação/recepção das mensagens; bem como são discutidas as noções de "acontecimento monstruoso" e do "presente hipertrofiado" característicos da sociedade midiática. Neste contexto, destaca-se a centralidade do telejornalismo junto à socialização de uma história pública, em muito dependente daquilo que a grande mídia seleciona e socializa em seus "enquadramentos da memória social", seja em relação ao passado, seja frente aos registros do tempo presente e imediato.

Palavras-chave: Fontes Telejornalísticas. Sociedade Midiática. Metodologia.

\section{Para citar este artigo:}

PALHA, Cássia Rita Louro. Fontes telejornalísticas nos domínios de Clio: notas metodológicas. Tempo e Argumento, Florianópolis, v. 9, n. 22, p. 236 - 258, set./dez. 2017.

\section{Cássia Rita Louro Palha}

Doutora em História pela Universidade Federal Fluminense (UFF). Professora do Programa de Pós Graduação em História da Universidade Federal de São João del-Rei. São João del-Rei, Minas Gerais - BRASIL palha17@gmail.com 


\title{
Sources of television
} journalism on Clio record: methodological notes

\begin{abstract}
The text focuses on theoretical and methodological notes aimed at analyzing telejournalism products, taking into account the narrative, resources and language codes of these products, the designing of their genres and formats, as well as research domains and sources available to the historian. Based on contributions from Pierre Bourdieu and British Cultural Studies the system of exchanges among realms concerning the production, the text and the circulation and reception of messages is approached. Typical concepts of media society like "monstrous event" and the "hypertrophy of the present" are discussed as well. In this context, the centrality of television journalism is highlighted alongside the socialization of public history which is largely dependent on what the mainstream media select and socialize in their "frameworks of social memory", either related to the past or to the records from present and immediate time.
\end{abstract}

Keywords: Sources of Television Journalism. Media Society. Methodology.

O historiador Pierre Nora (1979, p.181), em seu texto "O retorno do fato", problematizou na década de setenta do século passado não só a periodização tradicional da história contemporânea, mas também o que chamou de "circulação generalizada da percepção histórica" propiciada pelos meios de comunicação. Algo que em seu entendimento seria tributário da construção e socialização do fato histórico na "era dos mass media", os responsáveis pelo monopólio da própria história a partir daquele momento. A abordagem de Nora é motivadora para as discussões em torno da cultura 
histórica na esfera pública a partir dos meios massivos, especialmente no tocante a um objeto de pesquisa ainda pouco explorado na área, a televisão, e com ela, o seu gênero telejornalístico. Apesar das variadas possibilidades abertas com as transformações do panorama midiático de nossos dias, o telejornalismo continua sendo um elo fundamental da engrenagem produtiva de socialização de notícias da escala regional à planetária. Até mesmo pelo nível de intimidade construído na lida ordinária com o grande público desde meados do século XX, os telejornais se afirmaram como uma agenda informacional diária, um espaço em que os registros do passado e do tempo presente e imediato ganham não só visibilidade, mas existência social em nosso cotidiano. Nesse processo, interessa-nos sua gestão privilegiada nos enquadramentos da memória coletiva (POLLAK, 1992), selecionando sob a batuta do espetáculo midiático aquilo que Le Goff (1984) afirmou ser, na operação da memória, a arquitetura de interesses em torno das lembranças e dos esquecimentos. Abordando este cenário a partir de notas teórico-metodológicas, o presente texto apresenta possibilidades de análise em torno dos produtos telejornalísticos, trilhando a partir da crítica dessas fontes os meandros de uma discussão mais ampla sobre a cultura histórica no tempo presente.

Pode-se dizer que grande parte da produção sobre a televisão e sobre o telejornalismo no país ainda está restrita às áreas da comunicação social, da ciência política e da sociologia'. Para Lima (2004, p. 254), apesar da plêiade de estudos realizados nessas áreas, não se pode afirmar, contudo, que exista junto ao campo do telejornalismo uma tradição consolidada de pesquisas no Brasil. Além disso, malgrado uma crescente produção acadêmica sinalizar enfoques diversificados sobre o telejornalismo, parte expressiva dos trabalhos tem se concentrado no telejornalismo nacional das respectivas redes de televisão, com destaque para o Jornal Nacional, da Rede Globo de Televisão. Caminho compreensível pela centralidade que a emissora angariou na arena político-

\footnotetext{
${ }^{1}$ No que diz respeito à televisão, segundo o levantamento de Freire Filho (2004, p. 27), parte significativa dessas obras tiveram como principal parâmetro analítico a relação entre poder e capital na estruturação do setor televisivo, pautando-se por uma abordagem de forte cunho ideológico e memorialista, carente de espaço tanto para dados empíricos mais consistentes, quanto para a dimensão de uma produção cultural altamente híbrida, diversificada e complexa como a da mídia televisiva. Já a partir das décadas de 1980/90, novas abordagens tomaram forma, com a televisão sendo pesquisada a partir de suas múltiplas relações com o social, com destaque tanto para a análise dos produtos televisivos específicos, seus formatos e gêneros, quanto para o âmbito de suas audiências.
} 
cultural brasileira a partir de um campo de mídia eletrônica historicamente oligopolizado como o nosso.

Seguindo os rumos da própria televisão - que com menções honrosas a pioneiros do cenário internacional como Asa Briggs e Jean-Noel Jeanneney ${ }^{2}$, permanece em grande parte ignorada nos domínios de Clio - o gênero telejornalístico, seja como fonte ou como objeto de estudos, compartilha por tabela a mesma trilha de ostracismo. Busetto (2010, p. 156-57) sinaliza que mesmo entre territórios afins como o da imprensa - em que temos uma produção historiográfica significativa - não há, na maioria das vezes, um diálogo que contemple a esfera do telejornalismo, ou seja, não é considerada a interligação entre campos que necessariamente orbitam no universo comum da produção de notícias:

Historiadores da imprensa não se ocupam em conhecer quanto do material jornalístico publicado é devido à concorrência geral entre jornalismo impresso e telejornalismo, aos intercâmbios de práticas entre as duas formas de fazer jornalismo, às cumplicidades tácitas ou aparentes entre os dois tipos de jornalismo. E tampouco eles buscam mensurar o quanto do material jornalístico selecionado é resultante de fatos como: o periódico analisado integrar-se a um conglomerado comunicacional que conta com emissora de TV; o proprietário de jornal encontrar-se na luta por uma concessão televisiva; ou ainda, o dono do jornal não dispor de canal televisivo, quer em função de sua crença na autonomia do jornalismo impresso em relação ao telejornalismo - uma vez que a operação de uma emissora de TV depende de concessão do poder público -, quer simplesmente por dificuldades financeiras que 0 impeçam de ingressar no campo televisivo.

Não obstante, há ainda um desafio básico a ser vencido no trato com a pesquisa voltada ao telejornalismo: o acesso às próprias fontes. Pesquisadores da área são enfáticos na denúncia à falta de acessibilidade aos arquivos das emissoras brasileiras e à total ausência de uma política pública de preservação do patrimônio televisivo nacional. Se por um lado, há a preocupação com o estado de conservação do pouco acervo já disperso das emissoras pioneiras, por outro lado, o espólio do material televisivo que foi

\footnotetext{
2 Segundo Busetto (2010, p. 157), enquanto o britânico Asa Brigs inicia suas pesquisas em 1958, o francês Jean-Noel Jeanneney tem sua produção evidenciada na passagem da década de 1970 para 1980. Os momentos diferenciados da arrancada das pesquisas sobre a radiodifusão, por parte dos autores, demarcam nas palavras de Busetto, o contexto histórico em que "seus países de origem vivenciaram a quebra do monopólio estatal no setor de emissão televisiva".
} 
concentrado nas mãos das emissoras privadas que possuem arquivos organizados, são praticamente inacessíveis ao pesquisador. Em contrapartida, ao lado de acervos com gravação de telejornais nacionais e regionais que têm sido constituídos em universidades e diversas organizações acadêmicas 3 e dos arquivos dos Museus da Imagem e do Som do país, o YouTube também tem ocupado um espaço fundamental de acesso a fontes, disponibilizando, apesar da fragmentação do material, diversificados registros televisivos atuais e passados, com recortes de edições telejornalísticas de variadas emissoras, inclusive das já extintas.

As abordagens em torno dos telejornais são variadas e podem contemplar desde a análise de representações sociais e de acontecimentos emblemáticos de uma história imediata (CHAVEAU, A.; TÉTARD, 1999) até os "usos do passado" em seus enquadramentos da memória social. Da análise situada de um telejornalístico regional em um dado contexto à abordagem comparativa entre telejornalísticos nacionais e/ou estrangeiros; do estudo das audiências ao campo de suas produções; dos canais de informação alternativos ao enfoque da trajetória editorial de programas; são muitas as possibilidades abertas ao pesquisador. Independentemente das escolhas e dos recortes que se faça, no início da caminhada é necessário um olhar atento tanto para os caminhos de estruturação do setor televisivo no país quanto para a configuração do próprio campo jornalístico em que o programa se insere. Em outras palavras, o estudo de um determinado telejornalístico não deve prescindir da compreensão das variadas articulações que ligam o posicionamento de sua emissora/filiada em um cenário de disputas e interações diversas junto aos demais concorrentes e produtos do campo jornalístico (BOURDIEU, 1997) instituído, que possui um modus operandi próprio a ser considerado como espaço social da indústria da informação.

\footnotetext{
3 Destaco o DOXA (Laboratório de Pesquisa em Comunicação Política e Opinião Pública) do IUPERJ, com registros de telejornais a partir do ano de 1988. Já na frente de trabalho da recepção telejornalística e televisiva como um todo, uma rica documentação dos índices de audiência do IBOPE pode ser encontrada no Acervo Edgar Leuenroth da Unicamp, ao passo que no acervo "TV-Pesquisa" da PUC Rio, disponível on line, têm-se além de jornais, um número expressivo de revistas, textos e produtos com recorte pontual de críticos da mídia impressa especializada em TV.
} 


\section{1) O modelo de "Codificação/decodificação" de Stuart Hall4: entre frentes e fontes de trabalho}

Antes de se pensar nas particularidades da fonte telejornalística, é preciso contextualizá-la a partir das engrenagens do processo comunicativo que a televisão abrange. No campo teórico sobre a televisão ao longo do século $\mathrm{XX}$, muitos caminhos poderiam ser esboçados. Considerarei aqui, para além da tradição pragmática e behaviorista da Escola Americana e dos teóricos da Escola de Frankfurt, a produção dos Estudos Culturais Ingleses que, a partir dos anos 1960, constituíram-se em um importante divisor de águas no campo da cultura, tomando forma a partir dos nomes de Richard Hoggart, de Raymond Willians e de Edward P. Thompson. Tendo como contexto as aspirações da classe operária inglesa, o grupo tinha como base analítica original a obra do teórico italiano Antônio Gramsci, o que implicou em outras palavras, numa abordagem da cultura amplamente voltada para o processo de transformação social ligada ao cotidiano dos sujeitos e de suas lutas no campo social5. Antes das pesquisas inauguradas pelo grupo inglês, grande parte dos trabalhos sobre comunicação de massas concebia o processo comunicativo como um circuito linear entre emissão, mensagem e recepção. Numa perspectiva exclusiva de simples troca de mensagens, desconsideravam a análise desses momentos diferenciados enquanto partes de um complexo fluxo de relações.

Stuart Hall, que assume a direção do grupo na década de 1970, promove um novo marco dentro dos estudos sobre a televisão com 0 texto “Codificação/decodificação”, questionando essa visão mecanicista e linear. É na intenção de evidenciar, ainda que panoramicamente, essa nova perspectiva ${ }^{6}$ e suas frentes de trabalho para o pesquisador, que resgato a seguir as principais questões abordadas pelo autor nesta obra publicada originalmente em 1980. O eixo de articulação da abordagem de Hall é pautado tanto na autonomia relativa de cada um dos momentos do processo televisivo (produção, forma-mensagem, circulação/recepção) quanto na importância da

\footnotetext{
${ }^{4}$ Esta parte em especial é uma adaptação das notas metodológicas de minha tese de doutoramento, cf. Palha (2008).

${ }^{5}$ A respeito dos Estudos Culturais Ingleses e sua influência na América Latina, cf. Escosteguy (2001).

6 Uma revisão crítica do modelo de "Codidicação/decodificação" é delineada pelo próprio autor em "Reflexões sobre o modelo de codificação/decodificação: uma entrevista com Stuart Hall” (HALL, 2003, p. 353-386).
} 
articulação desses momentos junto ao circuito como um todo (HALL, 2003). Isso significa considerar que o pesquisador que resolva, por exemplo, concentrar sua análise empírica na crítica da forma-mensagem dos textos televisivos 7 , não pode ignorar suas instâncias de produção e de circulação/recepção, as quais, apesar de demarcarem momentos distintos, estabelecem laços concretos junto à construção do conteúdo produzido.

Diante das muitas opções possíveis no trabalho de crítica junto aos textos televisivos, que vão das tradicionais análises de discurso e de conteúdo às variadas abordagens de base semiótica, Hall ressalta que os elementos de registro da linguagem audiovisual que agregam sentido ao conjunto do texto ganham significado de análise metodológica quando são desconstruídos. O que não significa uma desconstrução por ela mesma, mas sim um desmonte da mensagem que vê cada momento de desconstrução a partir do todo que a obra encerra, onde em especial, caberia ao pesquisador a análise dos sentidos preferenciais ou dominantes presentes no conjunto da obra. Em suas palavras:

Ao falarmos de sentidos dominantes, então não estamos nos referindo a um processo de mão única, que governa a forma como todos os acontecimentos serão significados. Esse processo consiste no trabalho necessário para fazer cumprir, conquistar plausibilidade para exigir legitimamente uma codificação do evento dentro do limite das definições dominantes nas quais esse evento tem sido significado conotativamente. (HALL, 2003, p.396-398)

Longe de uma perspectiva estanque, Hall define os sentidos dominantes ou preferenciais presentes em um texto como aqueles pertencentes a um estágio relativamente consolidado das referências do universo popular, compondo assim o senso comum de uma época e lugar. Sob este ponto de vista, os sentidos preferenciais visam antes de tudo, a uma tentativa de construção de consenso. Porém, dentro do mesmo referencial gramsciano, o autor deixa clara a capacidade de ressignificação dos sujeitos que nunca são passivos a essas mensagens. Ou seja, os sentidos preferenciais, apesar de seus efeitos concretos nunca são bem sucedidos em sua integralidade, representando apenas um exercício de direção junto à leitura da audiência.

\footnotetext{
7 Texto entendido aqui como o conjunto de signos pertencentes a um "determinado universo de discurso delimitado por um código seja este qual for e que é transmitido sobre a base de um suporte físico distinguível da conduta dos receptores" (VÉRON, 1977, p. 154).
} 
Voltando para as instâncias do processo comunicativo, Hall define o momento da produção como o espaço em que são permanentemente construídas as práticas da rotina de trabalho, do conhecimento institucional, dos conceitos profissionais e das habilidades técnicas de suas equipes. Algo que converge para o que Bourdieu (1997, p.9) caracteriza como o espaço do habitus profissional, que de maneira geral, refere-se a princípios geradores de práticas específicas decorrentes de uma percepção compartilhada que os sujeitos interiorizam ao longo de trajetórias no mesmo universo, o que envolve não apenas o lado pragmático das rotinas da produção profissional dos sujeitos, mas sua dinâmica interna e a própria relação dos agentes entre si. Desta forma, o pesquisador poderá se utilizar da história oral, de registros biográficos, de documentação e dados institucionais que permitam identificar os integrantes da equipe do telejornalístico, suas trajetórias de vida e formação, seus posicionamentos, divergências e disputas internas junto ao campo. Muitas das vezes, mudanças no formato ou na linha editorial de um telejornalístico podem ser evidenciados a partir dos registros dessa frente de trabalho. Hall ainda enfatiza que, embora as estruturas de produção da televisão originem os discursos televisivos, elas não constituem um sistema fechado. Pelo contrário, elas retiram "assuntos, tratamentos, agendas, eventos, equipes, imagens de audiência, 'definições da situação' de outras fontes dentro da estrutura sociocultural e política mais ampla da qual são uma parte diferenciada" (HALL, 2003 p. 389-390).

Nesta perspectiva, a circulação e a recepção constituem igualmente momentos do processo de produção da televisão, a partir da reincorporação de uma série de "feedbacks indiretos". Assim, a recepção não encerra o momento da transmissão do conteúdo televisivo, mas abre-se para mediações (BARBERO, 2001) nas quais as mensagens são ressignificadas pelos sujeitos, transitando num processo contínuo de codificação/decodificação em que os vários agentes sociais são ao mesmo tempo consumidores e em certa medida, também produtores das mensagens ${ }^{8}$. Para Bourdieu (1997), trata-se dos processos de individualização das mensagens, considerando-se os

\footnotetext{
${ }^{8}$ Hall chega a delinear momentos distintos de mediações em que a recepção da mensagem pode seguir a padrões dominantes, convergindo com os interesses em princípio estabelecidos pelos produtores; a padrões negociados, nos quais se aceitam alguns significados já existentes, mas atribuindo-lhes outros tantos e opositora, em que o indivíduo interpreta a mensagem em sentido oposto ao que foi conferido em sua origem.
} 
esquemas prévios estabelecidos nessa recepção ativa, baseada na posse e distribuição desigual do capital cultural relativo dentro de um sistema capitalista. É certo que muito se pesquisou nas últimas décadas no campo da recepção do ponto de vista qualitativo, especialmente através da etnografia e da prática de entrevistas, e por consequência, muitas posições foram revistas e aprofundadas desde as primeiras publicações da área. Não sendo esse o momento de abordagem para tais análises, ressalto apenas que do ponto de vista mais quantitativo e seriado, o historiador que não tiver por objeto a centralidade da recepção, mas sim o mapeamento de alguns de seus indicativos, poderá ainda trabalhar com fontes ligadas aos índices de audiência, bem como com a crítica especializada em jornais e revistas.

\section{2) A fonte audiovisual televisiva e o telejornalismo}

A fonte audiovisual, mais precisamente a televisiva, faz uso de uma linguagem que em princípio se apresenta ao grande público de forma plenamente acessível, universalizada. Contudo, trata-se de uma linguagem de alta complexidade e hibridização que comporta entre outros elementos: a integração de sons e imagens em sintonia fina; o ritmo acelerado de seu fluxo com cortes rápidos; o jogo de interesses dos enquadramentos, dos movimentos e ângulos de câmera; a construção de cenários e a escolha de figurinos; a iluminação; a trilha sonora; as opções de montagem; a fragmentação e a diversidade de outras textualidades e códigos midiáticos ${ }^{9}$. Trata-se ainda de uma linguagem que tende a fundir os meandros da realidade com a ficção. Mesmo junto ao extremo dos telejornais com sua narrativa do "real”, do "verídico", o pesquisador vai se deparar com inserções outras que em princípio fariam parte do mundo do ficcional. O mesmo se pode dizer de telenovelas que misturam a narrativa ficcional com cenas e pautas de acontecimentos reais. É a partir dessa tessitura híbrida que o público constitui uma identificação mais imediata com seu próprio universo subjetivo que

\footnotetext{
${ }^{9}$ Mesmo no âmbito acadêmico, tais elementos por vezes são negligenciados. Napolitano adverte o quanto a valorização verticalizada do código verbal em detrimento dos demais, em pesquisas de produtos audiovisuais, acaba por limitar a construção de sentido da obra. Em suas palavras, "o problema está em isolá-lo dos outros códigos, canais e técnicas que estruturam o documento como um todo e que remetem a linguagens específicas, complexas e sofisticadas, que não se resumem ao parâmetro verbal" (NAPOLITANO, 2005, p. 267).
} 
não faz separações estanques destas dimensões. O "atentado de 11 de setembro" configurou-se como um caso singular nesse sentido. Mauad (2007), ao analisar sua cobertura pela imprensa traça um diálogo profícuo com o campo cinematográfico e televisivo, apontando para sensação de déja vu que as imagens das Torres Gêmeas sendo atingidas pelos aviões despertaram no imaginário das audiências, que se reportaram a produções como Armageddon ou Independence Day (MAUAD, 2007, p. 257-258). Já o linguista Patrick Charaudeau (2006), que pesquisou o atentado pelas reportagens televisivas, evidenciou a similitude das narrativas tanto aos roteiros de filmes de catástrofes quanto às tradicionais reportagens de guerra, a partir do denominador comum composto pelas vítimas, pelos responsáveis e pelos eternos e providenciais salvadores (CHARAUDEAU, 2006, p. 244).

É a partir dessa lógica discursiva maior que os gêneros televisivos podem ser entendidos não de forma rígida e padronizada, mas como o que Barbero (2001, p. 314) chamou de estratégias de comunicabilidade, em que talvez a marca mais evidente de sua unidade seja sua promessa de acesso a um mundo específico (JOST, 2004, p. 33), o que não significa, como abordado acima, a restrição ao trânsito por "outros mundos" em seus códigos e textualidades diversas. Assim, no caso dos telejornais, o que prepondera é uma informação que carrega consigo a promessa de acesso ao "real", a um testemunho inconteste do mundo, especialmente nas coberturas ao vivo. Se por um lado, essa seria uma promessa ontológica do telejornalismo, por outro lado, seus subgêneros (telejornalismo policial, de esportes, variedades, documentários...) abrigam uma grande variedade de produtos com formatos bem distintos. Exemplos como Cidade Alerta, da TV Record, o Jornal Nacional, da Rede Globo e mesmo o CQC, da TV Bandeirantes, nos dão o tom dessa variedade possível a partir de estratégias discursivas totalmente díspares. Ao pesquisador cabe então o mapeamento dessas especificidades que caracterizam dentro do leque de subgêneros o formato do programa a ser analisado e de como nele foram apropriados os elementos da linguagem televisiva.

Nas pesquisas em torno dessa promessa do telejornalismo, muito já se discutiu sobre a construção de seus critérios na busca de uma pretensa imparcialidade e autenticidade na cobertura dos fatos, mas pouco se debateu sobre as manipulações de 
contexto estrategicamente plantadas em alguns noticiários, como se o falseamento puro e simples, também não pudesse ocorrer. Como Bloch (2001) já nos deixou o legado do quanto os falseamentos podem nos falar do tempo de uma sociedade e de seus interesses, retomo aqui um exemplo abordado por Ferrés (1998), que muito contribui para pensarmos a construção de contextos e a formação da opinião pública a partir dos abusos dessa promessa ontológica das veiculações jornalísticas. Trata-se do emblemático exemplo da guerra do Golfo em agosto de 1990, quando após a invasão do Kuwait por tropas iraquianas, a televisão americana exibiu o chamado "escândalo das incubadoras". Contando com o depoimento emocionado de uma jovem que figurou como testemunha, a notícia disseminada foi a de que soldados do Iraque teriam invadido hospitais e desligado tubos de oxigênio das incubadoras neonatais, deixando pelos corredores os corpos das crianças mortas. O impacto do escândalo das incubadoras no senado americano foi grande e a aprovação da intervenção armada dos EUA no conflito não tardou. Daí para frente, como sabemos, os americanos se mobilizaram em favor da política de intervenção bélica do presidente Bush e passamos a acompanhar uma guerra que aos moldes estéticos de uma batalha de videogame estreou por tempo significativo o espetáculo midiático. Mais tarde, descobriu-se que a testemunha entrevistada era a filha do embaixador do Kuwait nos Estados Unidos e que o episódio tinha sido estrategicamente construído com o objetivo de incriminar as tropas iraquianas (FERRÉS, 1998, p. 168-69).

Nos limites da exceção que este tipo de exemplo mais diretivo nos leva, é interessante perceber que se sofremos de uma inflação acontecimental nos dias atuais, paradoxalmente essa mesma tormenta de informações também nos limita. Frente à falta de decantação temporal, a possibilidade de uma reflexão crítica é sempre limitada, e é neste sentido que Nora vai defender que, assim como na economia monetária, o acontecimento midiatizado sofre "com o abandono da garantia" (apud DOSSE, 2013, p. 263). Recentemente abordando a falta de credibilidade da mídia atual, Ramonet (2013) destacou que mediante a rapidez e a concorrência entre os diversos meios massivos do mercado, o jornalista já não tem mais condições de verificar várias fontes para estabelecer seus critérios em torno do que é ou não fiável. Para o autor, se a credibilidade 
do jornalismo informativo não estivesse em crise, não teria surgido nos últimos tempos nos EUA o jornalismo sem fins lucrativos e o próprio Wikileaks. O exemplo das incubadoras nos leva ainda a duas outras considerações em torno da indústria da informação: os usos do sensacionalismo e a fragmentação seletiva em torno daquilo que se informa. Quanto ao primeiro, sabemos o quanto ele possui fortes efeitos no mundo perceptivo das audiências. Contudo, na mesma medida em que o sensacionalismo mobiliza e seduz a partir da lógica do espetáculo em que é convocado, o exagero ao apelo da emoção pode igualmente depor contra o acordo tácito de uma suposta isenção estabelecida entre o telejornalístico e o seu público. O certo é que no limite da dose se encontram os próprios desdobramentos que o evento, por vezes, passa a angariar na circularidade do campo jornalístico como um todo. Já no que diz respeito à fragmentação, o telejornalismo proporciona uma parte sempre delimitada do "elefante branco" que lhe interessa destacar pelo crivo de um ponto de vista determinado, construindo recortes situados e na maioria das vezes descontextualizados em torno dos fatos. Nesta direção, a fragmentação seletiva dos acontecimentos, aliada ao apelo emocional, constituem parte dos elementos através dos quais Nora (1979, p.185) vai tratar a participação das audiências como "exigente e alienada, voraz e frustrada (...), autônoma e teleguiada como essa implacável realidade da vida contemporânea que se chama opinião".

Passo a pontuar, a seguir, dentre os muitos aspectos possíveis e relevantes na crítica interna dos telejornais, aqueles que considero mais centrais e que podem auxiliar os primeiros passos da investigação. Tais elementos estão intimamente relacionados e a pontuação mais categórica que se segue tem por motivação apenas uma apresentação mais didática das possibilidades do olhar do pesquisador.

\section{1) Estrutura do programa:}

a) Lugar/papel dos sujeitos: importância de apresentadores e repórteres na articulação do programa e na construção da credibilidade; presença de entrevistados e especialistas (papel de informação/opinião). Ressalta-se a importância dos apresentadores ou âncoras dos telejornalísticos que na maioria das vezes são como "a 
marca de credibilidade" do programa, os responsáveis por toda a organização narrativa do telejornal, regendo a arquitetura do formato apresentado.

b) Narrativa e relação estabelecida com o telespectador: análise da construção predominante do texto verbal, seja na forma de discurso, de uma discussão ou de um relato, vocabulário escolhido e postura mais diretiva adotada na relação com o telespectador. É a partir da relação que a narrativa constrói com o telespectador que a promessa (JOST, 2004) é construída e que sabemos o que ele tem a oferecer como produto de informação.

c) Recortes em reportagens específicas: identificação dos sujeitos e das motivações de seus discursos; no caso de notícias conflitantes, verificar se opiniões divergentes foram contempladas e como foram veiculadas; análise da condução adotada frente a fatos polêmicos, bem como presença de maniqueísmos, estereótipos e esquematizações na apresentação das informações.

d) Grade de notícias e temáticas: verificar o número de notícias e de blocos a partir de sua ordem, hierarquização e duração; observação da variedade (campos da política, economia, cultura) e do nível de gradação temática ao longo do telejornal, como notícias fortes no início e as agradáveis e leves no final; número e duração de inserção dos chamados fait-divers ou ainda dos "fatos-ônibus"10. No caso de telejornalísticos especiais, com uma veiculação semanal ou mensal, observar a variação das temáticas escolhidas, o que para o pesquisador interessado em recortes amplos da trajetória de um programa pode oferecer referências importantes sobre sua linha editorial.

\section{e) Fragmentação seletiva, construção de contextos e sensacionalismo:} observação do nível de fragmentação da notícia, característica que costuma ser predominante em detrimento de uma abordagem mais contextualizada dos fatos;

\footnotetext{
${ }^{10} \mathrm{O}$ aspecto político dos fatos ônibus ou das notícias de variedades consistem, para Bourdieu, no apelo da popularidade, "porque interessa a todo mundo sem ter conseqüências e porque ocupa tempo, tempo que poderia ser empregado para dizer outra coisa" (BOURDIEU,1997, p. 23). A política de exacerbação da linha fait divers na direção de jornalismo da Rede Globo por exemplo, foi seriamente criticada quando o Jornal Nacional, de 28 de julho de 1998, ocupou mais de dez minutos de sua programação na veiculação do nascimento da filha da apresentadora da mesma emissora, Xuxa, ao passo que o leilão da Telebrás e da Telesp, que iria acontecer no dia seguinte, ficou com menos de quatro minutos. Outra polêmica foi a referente às três extensas reportagens que o mesmo jornal exibiu sobre o triângulo amoroso de Capitu, Eliseo e Otelo, três macacos do Zoológico de Brasília, levados ao ar no mesmo ano.
} 
avaliação de possíveis manipulações de contextos e de dados de informação; atentar para a utilização do apelo emotivo e sensacionalista junto a acontecimentos de impacto social envolvendo desastres e mortes.

f) Edição, montagem e ritmo: análise dos recortes seletivos realizados e de como foram equacionados os elos de continuidade e de ritmo do programa, seu dinamismo e adequação de suas pausas no fluxo de sequência das reportagens.

\section{2) Elementos da linguagem audiovisual:}

Apesar da linguagem audiovisual envolver imagens e sons em sintonia fina, dando uma aparência quase sempre uníssona ao sentido do texto televisivo, é preciso considerar que ambos possuem seus níveis de autonomia e de especificidade. Além disso, imagem e som estão submetidos a canais e recursos variados que organizam e direcionam o documento como um todo. Destaco abaixo alguns elementos dos recursos imagéticos e sonoros que, apesar de não esgotarem o repertório de possibilidades analíticas, oferecem um olhar panorâmico das formas de apropriação do audiovisual pelo telejornalismo.

\subsection{1) Recursos Imagéticos:}

a) Planos e enquadramentos de câmera: Pode-se verificar nos telejornais uma certa constância nas escolhas de planos e enquadramentos e mesmo de posturas e gestuais de apresentadores e repórteres - o telejornalismo corresponde a um dos gêneros mais rígidos da televisão (MACHADO, 2001) - em que a repetição estabelece regimes de segurança e credibilidade ao telespectador. Nos enquadramentos, a perspectiva do olhar do telespectador é sempre dada pelas escolhas da objetiva da câmera. No close, a mensagem é a da atenção absoluta para o objeto da filmagem. Na veiculação de um depoimento, por exemplo, criam-se laços fortes de veracidade e de aproximação emocional com o público, que passa a se relacionar com a personagem de forma mais intensa. O plano médio ou próximo é o mais utilizado pelo telejornalismo ao veicular seus apresentadores da bancada ajudando a estabelecer um contato de credibilidade e competência a partir de um ponto de vista dirigido. Já no plano geral, o contato do telespectador com o que é apresentado é mais da ordem do inteligível. A câmera integra o objeto de filmagem a uma noção de conjunto, que tende a ressaltar o contexto e a dissolver a 
personagem (HERNANDES, 2006, p. 138-39). Em outra perspectiva, a observação dos ângulos pode ser especialmente interessante na filmagem de personalidades. Com a câmera alta, o movimento do foco é de cima para baixo, provocando um achatamento da imagem, indicando uma inferioridade do que é enquadrado. Já na câmera baixa, o movimento é exatamente o inverso, o ângulo valoriza as dimensões da personalidade enquadrada dando-lhe uma visibilidade ampliada. (HERNANDES, 2006, p.140);

b) Composição, distribuição dos elementos de observação dentro do enquadramento;

c) Iluminação (tênue, uniforme, intensa, contrastante) e ambientação do programa como espaço comunicativo (presença de bancada, mesa redonda, repórteres de redação ao fundo, composição de cenário, espaços para apresentação de gráficos, mapas, anagramas...);

d) Conjunto de recursos humanos, gráficos e técnicos (FERRÉS, 1996): uso de imagens de arquivos, testemunhos, cartazes, vinhetas, recursos digitais, teleprompter, chromakey... No caso específico da observação de apresentadores e repórteres, é possível identificar a postura adotada pelos profissionais, o tipo de figurino, a gesticulação, o posicionamento em "cena" visando princípios de credibilidade e aproximação com o público;

\subsection{2) Recursos Sonoros:}

a) Tom e ritmo de voz dos apresentadores (no Jornal Nacional da Rede Globo, por exemplo, o destaque das principais notícias que serão apresentadas, a chamada escalada, possui um tom professoral, intenso e com ritmo acelerado, diferentemente da tônica do encerramento do programa);

b) Relações que se estabelecem entre texto falado e imagem (reforço, comparação, antítese). Geralmente no telejornalismo convencional há uma sincronia entre o texto falado e a imagem, construindo uma relação de reforço ou de ilustração. Já no telejornalismo de documentários, a licença artística gera uma maior riqueza nos usos da imagem e do som junto à construção de sentidos. O Globo Repórter (anos 1970), que possuía em sua equipe vários cineastas, é exemplo de uma linguagem diferenciada nesta direção (PALHA, 2008);

c) Avaliação da introdução de músicas, efeitos sonoros e de som direto nas tomadas (função informativa, estética, dramática...).

Outra questão, para além dos recursos da linguagem audiovisual, merece ser considerada: as transformações na base técnica de registro do meio televisivo. Considera- 

o satélite, o videotape, a introdução de links ao vivo, a multiplicação de canais abertos e a cabo, o maior incremento dos mecanismos de interatividade e, hoje, com a convergência digital, têm-se a possibilidade de integração com os sistemas de informática, internet, telefonia celular, permitindo novas formas de audienciação (OROZCO, 2014) dos sujeitos. Para o pesquisador que tiver por objetivo a construção da história de um telejornalístico, as mudanças desta ordem são fundamentais para o entendimento do processo comunicativo materializado na linguagem do programa em seu contato com o universo social de seu público.

\section{3) Entre o tempo e o acontecimento midiático}

$\mathrm{Na}$ contemporaneidade, a dimensão da temporalidade e das memórias tangenciadas pela influência da grande mídia - espaço privilegiado de reconhecimento social - passaram a ser problematizados a partir das implicações do presentismo e de sua fugacidade. O bombardeio desenfreado das informações e das memórias comercializadas em massa nos levaria a uma crise em que as memórias cairiam facilmente no esquecimento, uma vez que, em sua maioria, não possuem lastros significativos com a experiência, seriam "memórias imaginadas" (HUYSSEN, 2000). Nessa síndrome de amnésia em meio à fartura de lembranças, teríamos cada vez mais uma cisão nos processos através dos quais construímos nossos laços identitários ou ainda, de consciência histórica (RÜSEN, 2001).

Perspectiva parecida pode ser encontrada no que diz respeito à noção da temporalidade, eixo central para a constituição de nossas identidades, mediadas a partir das renovadas tecnologias. Para variados autores, estamos vivendo um período marcado por um presente hipertrofiado (HARTOG, 2014; DOSSE, 2013; SARLO, 2005; entre outros). Concebida sob a forma de 'golpes' sucessivos sem relação reflexiva entre si, essa temporalidade estaria promovendo, em seu extremo, uma crise esquizofrênica de quebra das cadeias de significação do sujeito em função das dificuldades de se estabelecer 
alguma organicidade entre passado, presente e futuro (JAMESON, 1996). A percepção de Dosse em relação às veiculações telejornalísticas, especialmente as "ao vivo" e suas breaking news, parece caminhar neste sentido, quando o autor aborda sua contribuição para um "esmagamento das temporalidades, uma precipitação para esse presente hipertrofiado onde o passado e o futuro se realizam" (DOSSE, 2013, p. 297).

Nas transmissões diretas, o público é convocado a compartilhar a interação com um vivido já com aura de histórico, proporcionado pelo programa e ao longo de sua duração, fazendo com que o telejornalístico se torne uma janela privilegiada de acesso ao mundo real. Em tempos de imediatismo informacional e do estrondoso suporte de processamento de dados e informações que a maioria das grandes redações possuem, a manutenção, por exemplo, de correspondentes internacionais pelas agências visa antes de tudo sustentar essa promessa de testemunho. Testemunho do que já passou e atualização incessante do porvir que não é mais o futuro, já é o "agora”, proporcionado pelo link direto.

Sem querer restringir o telejornalismo ao recorte dos acontecimentos midiáticos, retomo nos limites deste texto esta discussão iniciada por Nora como forma de ilustrar alguns dos enfrentamentos do historiador do tempo presente. Para o autor, o acontecimento massivo deve ser considerado a priori pelas características singulares da sociedade a que pertence. Dentre os muitos exemplos destacados em sua obra, vejamos aquele apresentado como a representação mais acabada do acontecimento moderno, o caso da primeira alussinagem americana (NORA, 1979, p.185):

Tudo aí obedecia ao contraste explorado legitimamente pelos organizadores desse show interplanetário: inimaginável demonstração de poderio técnico realizado com essa precisão completamente onírica, superseleção dos três heróis com identificações com o tipo físico do superman das histórias em quadrinhos, utilização da estética futurista de onde emergiam na televisão escafandros livres do peso da Terra, contraste entre a emissão dos meios financeiros, humanos, políticos e a fragilidade dos reflexos físicos e nervosos de três simples homens; o imaginário fundamentado no superpoderio científico do mundo moderno alimentando-se aqui do mais antigo sonho da humanidade. Instância do real, instância informadora, instância consumidora caminhando ao mesmo tempo: o desembarque na Lua foi o modelo do acontecimento moderno. (grifo nosso) 
A junção desses elementos a partir da televisão - que para o autor, cumpre na modernidade o papel que o sino tinha na aldeia, o "ângelus da civilização industrial" tem como fio condutor a retransmissão direta dos fatos, projetando com intensidade até então inédita a teatralidade própria do acontecimento. É dessa maneira que ele é imediatamente construído no cenário público, tendo por base um voyerismo que "dá à atualidade tanto sua especificidade com relação à História quanto seu perfume já histórico" (NORA, 1979, p.185). Dentre as variadas nuances desse acontecimento moderno, Nora enfatiza sua relação com aquilo que há de mais banal no cotidiano, ativando o interesse do imaginário de massas; sua marcante fragmentação, capitaneada por uma descontextualização de apelo afetivo e sensacionalista e sua narrativa tangenciada pelo insólito e pelo espetacular da engrenagem midiática. Todos processados a partir de uma retro-alimentação comercial que, buscando sempre a novidade para fins de consumo, tenderia a transformar o acontecimento em algo se não “monstruoso" (NORA,1979, p. 183), por certo desafiador aos pesquisadores. É neste contexto em que a encenação do espetáculo acaba por destacar a parte não factual do acontecimento, que Nora (1979, p. 191) posiciona a crítica do historiador a partir da dialética entre o real e a imaginação, ou ainda a partir do "duplo sistema que se entrecruza nele, sistema formal e sistema de significação" em que para se evidenciar a rede de significações, não se trilha outro caminho senão o do

método seriado daquele do passado, com a diferença de que sua conduta tem por finalidade aqui, culminar no acontecimento em lugar de procurar reduzí-lo. Faz conscientemente surgir o passado no presente, em vez de fazer inconscientemente surgir o presente do passado.(...) $O$ acontecimento tem como virtude unir num feixe significações esparsas.Ao historiador cabe desuní-los para voltar da evidência do acontecimento à colocação em evidência do sistema.(...) Sobre a erupção do vulcão, o historiador do presente, repetimos, não toma parte, diferentemente do historiador do passado a quem a duração permite fazer artificialmente desses vulcões factuais tantas colinas-testemunhas de uma paisagem que ele baliza.

Nora deixa clara a inversão do olhar da observação crítica, em que o acontecimento seria apenas a culminância, o "ponto extremo do acumulado antes dele" 
(DOSSE, 2013, p. 297), o que envolveria fazer "surgir o passado no presente", resgatando o princípio de suas causas, a problematização dos feixes de sua significação temporal. 0 autor nos convoca desta maneira não para as implicações dos possíveis desdobramentos dos fatos - do qual não teríamos domínio - mas fazendo a analogia com os geólogos, chama nossa atenção para a identificação dos "níveis geológicos" dos vulcões, ou seja, da implicação de suas camadas temporais. Dessa maneira, se a forma como o acontecimento é construído e socializado nos diz muito de nossas sociedades e do sistema midiático em que estamos inseridos, sua crítica nos remete a um conjunto de representações marcadas por uma temporalidade que se condensa num presente cuja lógica não comporta sua densidade. Ao sabor dos frankfurtianos, pelo contrário, a reduz como mercadoria.

Nessa perspectiva, ao abordar a noção de acontecimentos midiáticos, Dosse destaca que os mesmos não devem ser lidos apenas como momentos isolados. Usando da figura da esfinge, por um lado, o autor aponta a desestruturante interrogação que sempre fica diante do acontecimento em seu imediatismo. Por outro lado, se a busca do acontecimento pelo seu passado é de fundamental importância neste sentido, o autor destaca que ela não é suficiente, pois além de esfinge o acontecimento é igualmente fênix, ou seja, está sempre em aberto, voltado para seus múltiplos desdobramentos, usos e possibilidades futuras. E se esse porvir traz consigo seus impasses, nossas possibilidades de trabalho estão nos múltiplos vestígios que o acontecimento deixa em sua relação permanente com os outros acontecimentos subsequentes. Assim, o amplo processo de socialização do acontecimento e da pluralidade de sentidos que ele assume no espaço público (DOSSE, 2013, p. 275) seria fundamental para a análise do historiador. O essencial estaria no vestígio do próprio acontecimento, "naquilo que ele se torna, de maneira não linear no interior dos múltiplos ecos de seu só-depois (après-coup)" (DOSSE, 2013, p. 339).

Ciente do quanto essa argumentação permeia um profícuo tópos de debates em torno dos impasses e das possibilidades da chamada história do tempo presente - que no recorte dessa proposta não tenho o objetivo de abarcar - destaco o exemplo de um acontecimento-mundo não muito distante, que nos reporta a esses "ecos" e especialmente a esses "usos" de sentidos de que nos fala Dosse. Trata-se da 
narrativização midiática do terrorismo a partir do ataque ao jornal francês Charlie Hebdo em janeiro de 2015. Na ocasião, em que durantes dias e semanas a fio os registros do ataque foram constantemente reatualizados, mobilizando a rede midiática internacional, várias empresas de comunicação no Brasil passaram a fazer uso do acontecimento visando a defesa de seus próprios interesses corporativos. A reboque da repercussão do caso retomaram com novo fôlego a bandeira de uma determinada "liberdade de expressão irrestrita", ideia presente em muitas das reportagens daquele contexto junto à cobertura das manifestações contra o ataque terrorista ao satírico jornal.

Sem esclarecer essa forçosa analogia com o caso francês e domando-a nas fronteiras da superficialidade do senso comum, seu uso político junto às audiências serviu para reforçar a máxima de que toda e qualquer forma de regulação do setor televisivo ou do universo da indústria da informação significaria uma volta aos tempos de barbárie da censura no Brasil. Se Dosse nos alerta sobre os novos desafios do acontecimento midiático "enigmático e indefinido" para o historiador, encerro por aqui este texto na chamada da trincheira que precisamos enfrentar junto ao jogo de interesses de discursos como estes, seja na condição de cidadãos, seja como pesquisadores dos meios massivos. O que implica resgatarmos nosso papel social junto à arena política-cultural do país onde a luta pela democratização de uma mídia eletrônica efetivamente plural ainda tem um longo caminho pela frente.

\section{Referências}

BARBERO, Martín. Dos meios às mediações: comunicação, cultura e hegemonia. Rio de Janeiro: Editora UFRJ, 2001.

BLOCH, Marc. Apologia da história ou o ofício de historiador.Rio de Janeiro: Jorge Zahar Editor, 2001. 
BUSETTO, Áureo. Sintonia com o contemporâneo: a TV como objeto e fonte da história. In: BEIRED, José Luís; BARBOSA, Carlos Alberto. (Orgs). Política e identidade cultural na América Latina São Paulo: Editora UNESP; São Paulo: Cultura Acadêmica, 2010. Disponível on line: (https://repositorio.unesp.br/handle/11449/110771, acesso em 17/06/2015).

BOURDIEU, Pierre. Sobre televisão. Rio de Janeiro: Zahar Editor, 1997.

CHARAUDEAU, Patrick. Discurso das mídias. São Paulo: Contexto, 2006.

CHAUVEAU, Agnès; TÉTARD, Philippe. (Orgs.).Questões para a história do presente. São Paulo: Edusc, 1999.

DOSSE, François. Renascimento do acontecimento. São Paulo: Editora Unesp, 2013.

ESCOSTEGUY, Ana. Cartografias dos estudos culturais: uma versão latino-americana. Belo Horizonte: Autêntica, 2001.

FILHO, João. Por uma nova agenda de investigação da história da TV no Brasil. In: Contracampo: Revista do Programa de Pós-graduação em Comunicação. Niterói: UFF, 2004.

FERRÉS, Joan. Televisão subliminar. Porto Alegre: Artes Médicas, 1998.

FERRÉS, Joan. Televisão e Educação. Porto Alegre: Artes Médicas, 1996.

HALL, Stuart. Codificação/decodificação. In: HALL, S. Da diáspora: identidades e mediações culturais. Belo Horizonte: UFMG; Brasília, 2003.

HARTOG, François. Regimes de historicidade: presentismo e experiências do tempo. Belo Horizonte: Autêntica, 2014.

HERNANDES, Nilton. A mídia e seus truques. São Paulo: Contexto, 2006.

HUYSSEN, Andreas. Seduzidos pela memória. Rio de Janeiro: Aeroplano, 2000.

JAMESON, Fredric. Pós-modernismo, lógica cultural do capitalismo tardio. São Paulo: Ática, 1996.

JOST, François. Seis lições sobre televisão. Porto Alegre: Sulina, 2004.

LE GOFF, Jacques. Memória. In: ROMANO, Ruggiero. (Dir.) Memória-História. Porto: Imprensa Nacional/Casa da Moeda, 1984. (Enciclopédia Einaudi, 1). 
LIMA, Venício. Mídia: teoria e política. São Paulo: Perseu Abramo, 2004.

MACHADO, A. A televisão levada a sério. São Paulo: Senac, 2001.

MAUAD, Ana Maria. Dimensões do presente: palavras e imagens de um acontecimento, os atentados ao World Trade Center e ao Pentágono em 11 de setembro de 2001. In: PORTO, Gilson Jr. História do Tempo presente. Bauru: Edusc, 2007.

NAPOLITANO, M. Fontes audiovisuais: a História depois do papel. In: PINSKY, Carla. Fontes históricas. São Paulo: Contexto, 2005.

NORA, Pierre. O retorno do fato. In: LE GOFF, Jacques; NORA, Pierre. (Orgs.) História: novos problemas. 2. ed. Rio de Janeiro: Francisco Alves, 1979.

OROZCO, G. Educomunicação: recepção midiática, aprendizagens e cidadania. São Paulo: Paulinas, 2014.

PALHA, Cássia. A Rede Globo e o seu repórter: imagens políticas de Teodorico a FHC. Tese de doutoramento. Programa de Pós-Graduação em História da Universidade Federal Fluminense. Niterói, 2008.

POLLAK, M. Memória e identidade social. Estudos Históricos, Rio de Janeiro, v.5, n,10, 1992.

RAMONET, Ignácio. Meios de comunicação: um poder a serviço de interesses privados? In: MORAES, Dênis; RAMONET, Ignácio; SERRANO, Pascual. Mídia, poder e contrapoder: da concentração monopólica à democratização da informação. São Paulo: Boitempo; Rio de Janeiro: Faperj, 2013.

RÜSEN, Jörn. Razão Histórica. Teoria da história: os fundamentos da ciência histórica. Brasília: Editora UNB, 2001.

SARLO, Beatriz. Tempo presente: notas sobre a mudança de uma cultura. Rio de Janeiro: José Olympio, 2005.

VÉRON, Eliseo. Ideologia, estrutura e comunicação. São Paulo, Cultrix, 1977. 
Recebido em 05/08/2017 Aprovado em 04/12/2017

Universidade do Estado de Santa Catarina - UDESC Programa de Pós-Graduação em História - PPGH

Revista Tempo e Argumento Volume 09 - Número 22 - Ano 2017 tempoeargumento@gmail.com 